\title{
"ENVELHECIMENTO SAUDÁVEL": A EDUCAÇÃO FÍSICA NO CONTEXTO DA SAÚDE, LINGUAGEM E MOVIMENTO HUMANO
}

\author{
Lisia Costa Gonçalves de Araújo ${ }^{1}$
}

ORCID: 0000-0003-2573-2403

VANDerléa ANA Meller ${ }^{2}$

ORCID: 0000-0002-5342-2659

Elaine Cristina Rodrigues Farina ${ }^{3}$

ORCID: 0000-0002-8239-1097

Resumo: O presente estudo busca compreender as práticas extensionistas da Educação Física com idosos no contexto da saúde, linguagem e movimento humano, com ênfase nas Práticas Integrativas e Complementares (PICS). As ações foram realizadas no projeto de extensão "Envelhecimento saudável", da UNIVALI, no trabalho com idosos em uma Unidade Básica de Saúde no município de Biguaçu, Santa Catarina. Tendo em vista a atuação foi possível evidenciar que os idosos reconheceram as PICS no contexto da educação em saúde; valorizaram as práticas de meditação realizadas, ampliando as percepções sobre o corpo e "ações comunicativas"; promoveram a atenção, a visão ampliada de corpo e capacidades

1 Doutora em Educação Física. Professora da Universidade do Vale do Itajaí (UNIVALI/SC), integrante do Projeto de Extensão "Envelhecimento Saudável”. E-mail: (laraujo@univali.br).

2 Doutora em Educação. Professora da Universidade do Vale do Itajaí (UNIVALI/SC), voluntária do Projeto de Extensão “Envelhecimento Saudável” E-mail: (vanderlea@univali.br).

3 Mestre em Ciências da Reabilitação Neuromotora. Professora da Universidade do Vale do Itajaí (UNIVALI/SC), voluntária do Projeto de Extensão "Envelhecimento Saudável”. E-mail: (farina. elaine@univali.br). 
expressivas; as relações socias harmoniosas foram favorecidas no diálogo; os desejos de saúde e cuidado de si e do outro foram manifestos nas práticas meditativas.

Palavras-chave: Extensão Comunitária. Envelhecimento. Saúde. Linguagem. Práticas integrativas.

\title{
"HEALTHY AGING": PHYSICS EDUCATION IN THE CONTEXT OF HEALTH, KINESICS AND HUMAN MOVEMENT
}

\begin{abstract}
This research pursues to understand the extensionist practices of Physics Education with the elderly in the context of health, language, and human movement, with emphasis on Integratives and Complementary Practices (PICS). The activities were performed in the UNIVALI's extension project "Healthy Aging" working with senior people in a Basic Health Unit in Biguaçu, Santa Catarina. It was possible to evidence through the activities that the population recognized the PICS in the sphere of health education; valued the meditation practices; expanded their perceptions of the body and "communicative actions"; promoted attention, amplified vision of the body and expressive capacities; harmonious social relations were fostered by dialogue, the health desires and the health care with yourself and the other were expressed in the meditation practices.

Keywords: Community-Institutional Relations. Aging. Health. Language. Integrative practices.
\end{abstract}

\section{"ENVEJECIMIENTO SALUDABLE": EDUCACIÓN FÍSICA EN EL CONTEXTO DE SALUD, LENGUAJE Y MOVIMIENTO HUMANOS}

Resumen: Este estudio tiene como objetivo comprender las prácticas de extensión de la Educación Física con los adultos mayores en el contexto de la salud, el lenguaje y el movimiento humano, con énfasis en las Prácticas Integrativas y Complementarias (PICS). Las acciones se llevaron a cabo en el proyecto de extensión "Envejecimiento saludable" de UNIVALI, trabajando con los ancianos en una Unidad de Salud Básica en el municipio de Biguaçu, Santa Catarina. En vista del desempeño, fue posible evidenciar que los ancianos reconocieron los PICS en el contexto de la educación para la salud; valoraron las prácticas de meditación realizadas, ampliando las percepciones sobre el cuerpo y las "acciones comunicativas", promovieron la atención, ampliaron la visión corporal y las capacidades expresivas, favorecieron las relaciones sociales armoniosas en el diálogo, los deseos de salud y autocuidado y por el otro, se manifestaron en prácticas meditativas.

Palabras claves: Extensión comunitaria. Envejecimiento. Salud. Lenguaje. Prácticas integradoras.

Submetido em: 27/08/2019.

Aceito em: 20/09/2019. 


\section{INTRODUÇÃO}

A extensão universitária envolve projetos e ações que buscam beneficiar educativamente a comunidade, nesse sentido, o projeto de extensão "Envelhecimento saudável", da Universidade do Vale do Itajaí (UNIVALI), propõe atividades, em consonância com as Práticas Integrativas, para os idosos atendidos nas Unidades Básicas de Saúde (UBS), no município de Biguaçu, SC. Foram valorizadas reflexões em torno da saúde intensificando ações comunicativas e linguagens presentes culturalmente; o reconhecimento do corpo expressivo como manifestação de sua presença no mundo, possibilitando ressignificar seu papel social.

Na proposta da Política Nacional de Práticas Integrativas e Complementares (PNPIC) está presente o incentivo formativo à equipe de saúde para que "[...] desenvolva ações de prevenção de agravos, promoção e educação em saúde - individuais e coletivas - [...] e práticas corporais e meditativas. (BRASIL, 2018, p. 34). O movimento humano merece especial atenção nesse cenário, pois é por meio dele que viabilizamos o dinamismo expressivo, criativo e comunicativo. As Práticas Integrativas e Complementares (PICS) foram definidas como dinâmicas de tratamento com recursos terapêuticos oriundos de conhecimentos tradicionais em prol da saúde (BRASIL, 2018). Entre essas práticas desenvolvemos as meditações, de modo mais específico, no seu potencial de ampliar as capacidades de sentir e pensar do ser humano.

Nas diferentes manifestações expressivas e linguagens com os idosos, por meio do yoga e meditação, buscamos a ampliação do movimento e fortalecimento humano na sua integralidade, bem como a quebra de paradigmas instrumentais e limitadores de expressão. Trabalhamos o movimento humano em uma perspectiva cultural, dinâmica e de expressão de significados, contrapondo os modelos instrumentais de exercício que buscam, limitadamente, o gesto perfeito, esquecendo do sentido do próprio movimento como aspecto fundamental do humano. A busca não foi pelo padrão de comportamentos “em si”, pois não há padrões pré-estabelecidos que mereçam ser atingidos, o que há são referências de ação, de aberturas para criarmos novas possibilidades de "sermos no mundo". Refletimos com os idosos sobre o engano objetivista que conduz às "verdades" pré-estabelecidas, e que nos teleguiam em terrenos limitados e mecanicistas, que somente ditam receitas de saúde. 
Nas áreas da saúde, nas perspectivas educativas e no universo científico, não podemos perder de vista a dimensão da linguagem, que é fator essencial, pois a linguagem é o próprio sujeito em transformação, é a expressividade e uma espécie de olhar para o mundo, um estilo de ser. A linguagem e o movimento humano estão profundamente relacionados à percepção humana, pois é a partir deles que criamos novas significações e sentidos, e dizer o que o ainda não foi dito, imprimindo um certo movimento às palavras, tornando o nosso discurso inédito. É justamente o caráter temporal da linguagem que nos dá condições de criar um novo discurso. Estamos lidando com a comunicação dos sujeitos, com sua expressividade e a fala tem atenção especial porque tangencia as dimensões perceptivas e simbólicas. As palavras são o desdobramento dos nossos corpos, terrenos de linguagens e dinâmicas comunicativas.

Não se trata de perseguir modelos, e sim de abertura de possibilidades ilimitadas, que nunca se esgotam pela própria natureza humana, que está sempre em transformação. É necessária a compreensão da dimensão da linguagem e da intersubjetividade nas temáticas da saúde, em especial coletiva, a fim de nos libertarmos do objetivismo excessivo, que nos destitui das práticas profissionais humanizadoras e críticas. Nesse contexto, realizamos também um passeio pela pragmática da linguagem, tendo como base a teoria do agir comunicativo em Habermas (2003) e pela fenomenologia francesa em Merleau-Ponty (2011).

Nos propósitos desse estudo, o objetivo envolve compreender as práticas extensionistas da Educação Física com idosos no contexto da saúde, linguagem e movimento humano, com ênfase nas Práticas Integrativas e Complementares (PICS).

\section{TRAJETÓRIA METODOLÓGICA}

Trata-se de um estudo de abordagem qualitativa, um estudo que envolve um passeio pela pragmática da linguagem, tendo como base a teoria do agir comunicativo em Habermas e na fenomenologia francesa merleaupontyana. Expressa um relato de experiência realizada no projeto de extensão "Envelhecimento Saudável” da UNIVALI, desenvolvido em uma Unidade Básica de Saúde (UBS) do município de Biguaçu, SC, e no Campus da Universidade. Foi realizada em 30 intervenções, desenvolvidas semanalmente, com 30 idosos de ambos os sexos.

As práticas corporais foram planejadas e desenvolvidas na dinâmica de oficinas com duração de 2 horas diárias. Os idosos foram acolhidos no ambiente 
das UBS e no Campus da Universidade por meio do diálogo e envolvimento nas práticas com oportunidades de expressão em diferentes linguagens e processos educativos em saúde.

\section{COMPREENDENDO AÇÕES DE EDUCAÇÃO EM SAÚDE}

A Educação em Saúde está amplamente envolvida nos propósitos das PICS, pois os processos educativos para a organização dos conhecimentos em saúde buscam a apropriação temática pela população e tratam de um conjunto de ações que contribuem para ampliar a autonomia das pessoas no seu cuidado e conquista de atenção de saúde a partir das necessidades (BRASIL, 2018).

Nas práticas com idosos, buscamos relações de atenção à saúde promovendo atividades que ultrapassassem os modelos curativos e avançassem no cuidado integral, com percepção de corpo sensibilizado e expressivo. As dinâmicas de meditação foram avanços na tomada de consciência corporal e reconhecimento da conexão entre sentir e pensar o corpo, integrando a compreensão dos estilos de viver e ser saudável.

A visão ampliada de saúde e de ser humano nas propostas realizadas foi constituída:

Considerando o indivíduo na sua dimensão global - sem perder de vista a sua singularidade, quando da explicação de seus processos de adoecimento e de saúde -, a PNPIC corrobora para a integralidade da atenção à saúde, princípio este que requer também a interação das ações e serviços existentes no SUS. Estudos têm demonstrado que tais abordagens contribuem para a ampliação da corresponsabilidade dos indivíduos pela saúde, aumentando, assim, o exercício da cidadania. (BRASIL, 2018, p. 8).

Envolvendo os propósitos educativos das PICS, buscamos atuações eficazes e participativas para refletir sobre a saúde dos idosos e ampliar as manifestações de movimento em diferentes linguagens. Foram propostas práticas que se desdobraram em meditações, com práticas relacionadas à Yoga, e diferentes brincadeiras também fizeram parte dessas dinâmicas meditativas. Organizamos momentos para exercícios respiratórios, de concentração e meditação (pranayamas) envolvendo a percepção corporal e autoconhecimento nas vivências da Yoga. Foi possível promover o relaxamento profundo por meio de posturas e processos de meditação. Para a idosa Ana "A meditação foi uma novidade na minha vida e aprendi a concentrar mais no que estou fazendo, sentindo que estou mais atenta”. As contribuições também permearam os aspectos cognitivos, de atenção e concentração, ampliando a memória e habilidades de movimento.

A meditação, de acordo com Brasil (2018, p. 80), é "procedimento que foca a atenção de modo não analítico ou discriminativo, promovendo alterações 
favoráveis no humor e no desempenho cognitivo". Nesse propósito, as práticas de meditação envolveram capacidades pessoais de concentração e relaxamento, ampliando a observação e atenção no autoconhecimento e cuidado, com liberdade para o imaginário e movimentação.

As estratégias foram pensadas com coerência e responsabilidade na organização do ambiente e recursos, garantindo a atenção e o direito à saúde. Com base na Constituição Brasileira de 1988, e com a implantação do Sistema único de Saúde (SUS) no Brasil, as conferências Internacionais de promoção de saúde ressaltam a necessidade de propostas de práticas humanizadas e mudanças de estilo de vida. As informações e ações são muito importantes no processo de transformação do ser humano para mudanças de hábitos. Dessa forma, foi importante a proposta que tornou as ações em saúde mais eficazes, transformando os modos de ser e viver e, consequentemente, melhorando a qualidade de vida.

Conforme a Lei no 8.080/90 nas disposições gerais Art. 2 - "A saúde é um direito fundamental do ser humano, devendo o Estado prover as condições indispensáveis ao seu pleno exercício". Também é necessário garantir redução de riscos de doenças e de outros agravos que assegurem acesso universal e igualitário às ações e aos serviços em saúde para a sua promoção, proteção e recuperação.

Nas práticas, com foco na saúde e linguagem comunicativa, o brincar, como manifestação livre expressiva e lúdica do humano, foi envolvido na realização das técnicas do yoga e os processos de meditação e relaxamento, quebrando referências sociais deturpadas de que brincadeira é coisa de criança. Durante as intervenções os idosos atribuíram significados ao brincar, identificados nas falas: "Estas brincadeiras fizeram parte das nossas vidas" (Idoso Paulo). Todos demonstram muita confiança e prazer nas práticas em virtude das relações com a infância; e relacionaram que "O idoso também pode brincar". (Idosa Maria). As correlações com as brincadeiras foram fundamentais nas diferentes linguagens envolvidas, facilitando os princípios posturais e possibilitando maior expressividade corporal, verbal e não verbal. Foi possível perceber a amplitude das emoções e entendimentos pessoais nas meditações, principalmente em torno da autoestima e autoconfiança, para agir e conquistar resultados benéficos à saúde.

Para Brasil (2018) a meditação possibilita as capacidades que envolvem observação e concentração em uma relação corporal equilibrada mental e física, regulando emoções e fenômenos com conteúdos que emergem à consciência, a fim de facilitar o autoconhecimento, autocuidado e autotransformação na interação em que o ser humano está envolvido.

Compreender as especificidades da população idosa foi um importante passo para construção de uma proposta qualificada em conjunto, com práticas desejadas 
e necessárias para o grupo. Consideramos que o corpo do idoso é repleto de histórias e sabedorias e tem, muitas vezes, grandes demandas de afeto e socialização, as quais fazem parte das suas histórias de vida. Portanto, ao trabalhar a percepção do corpo e seus significados, com práticas de educação em saúde, ocorreram expressões da realidade dessa população e desejos de viver.

Merleau-Ponty (2011) ressalta que o corpo não é somente o cruzamento de dados físicos, psíquicos e sociais, não é o objeto da biologia, psicologia ou sociologia é antes um ser no mundo. Assim como a geografia difere da paisagem, nosso corpo não é uma série de órgãos justapostos no ambiente, e tampouco um é o desdobramento do outro, eles estão em relação, estão envolvidos. Temos a posse do corpo, pois somos ele, porque somos um todo do qual dispomos, por meio do esquema corporal, no qual identificamos cada membro, não porque aprendemos a localização da perna esquerda ou direita, dos braços, coração, enfim dos órgãos, mas porque de algum modo eles se apresentam para o eu e abrem infinitas possibilidades. O nosso repertório vai se transformando ao longo dos tempos, e constantemente estamos refazendo nosso esquema corporal assumindo transformações em todos os aspectos.

Durante o processo das práticas envolvendo a meditação, os idosos experienciaram diferentes movimentos e sensações que possibilitaram sentir o corpo em conexão; ampliaram o repertório de habilidades de movimento e sensações que intensificaram a consciência corporal. Processos coordenativos foram promovidos com desafios cognitivos, físicos e sociais na interação com o outro e avanços na diversidade de movimentos. Cada um desejou superar suas limitações e conquistou maior mobilidade e relaxamento, foi possível no equilíbrio da ansiedade, na respiração profunda e diafragmática, focando a atenção para seu corpo e na percepção de si.

Foram práticas que despertaram a consciência de si e das capacidades pessoais, muitas lembranças foram retomadas em virtude das ressignificações e conquistas que remeteram às condições vividas no passado. Foi possível conhecermos e nos aproximarmos das histórias de vida de cada um, pois todos dialogaram e desejaram compartilhar seus sentimentos e lembranças, principalmente envolvendo as condições corporais e vitais. A abertura de consciência para a afetividade, coletividade e sociabilidade com confiança foi amplamente perceptível. Muitos idosos possuem histórias de vida muito parecidas e identificaram-se mutuamente em diferentes contextos e sentimentos, promovendo aproximações coletivas e entendimento de que não estavam sozinhos.

Nas atividades de extensão as transformações qualitativas e integralizadoras em torno da saúde foram desejadas. Criamos estratégias metodológicas que auxiliaram na compreensão de ações ampliadas para a compreensão da linguagem do "se movimentar" (Kunz, 2014), nela percebo que é o meu corpo inteiro que 
intenciona o movimento. Desde a ponta dos meus dedos a espacialidade do meu corpo se amplia, e de todas as partes há envolvimento para realizar potencialmente o movimento. A percepção de algo está vinculada a um mundo pré-objetivo do qual lanço mão, no momento em que me é solicitado. As minhas possibilidades motoras estão disponíveis como potência indivisa, e é por meio dos movimentos que realizo, que encontro algo no mundo, abrindo um campo perceptivo para, posteriormente, alcançar a coisa. Nesse sentido, vivo as situações sem antes me representar, pois tenho uma compreensão difusa, escorregadia do corpo e passo a compreender que o corpo é fundo para as coisas passarem a existir para mim. Sou dependente dele para entrar e permanecer no mundo como sujeito.

A amplitude humana que envolve a saúde e que as relações pessoais e com o outro foram importantes, principalmente por envolverem harmonia e paz. O reconhecimento das PICS, envolvendo a meditação, com o objetivo de implementar tratamentos alternativos à saúde e recursos terapêuticos, foram fundamentais para ampliar a visão de atendimento e conceito de saúde dos idosos. Reconheceram a saúde no cuidado, direito e quesitos necessários para a promoção, proteção e recuperação.

As ações de educação em saúde também foram ligadas ao Programa Saúde da Família (PSF), uma estratégia do Ministério da Saúde que contribui para a reorganização da atenção básica, aproximando os profissionais e comunidade, embasando-se em ações intersetoriais, interdisciplinares e considerando o indivíduo e sua inserção na família e na comunidade. Contudo, para alcançarmos as metas estabelecidas pelo SUS, buscamos atuar de acordo com os princípios de humanização, a fim de oferecer uma resposta positiva a demanda dos idosos, favorecendo contatos e diálogos mobilizadores do ser integral e da sensibilidade humana.

O trabalho envolvendo a meditação foi importante para os idosos por valorizar o corpo como espaço e tempo de expressão e linguagem, em sua consciência livre e criativa. Com foco na educação em saúde priorizamos os aspectos subjetivos como ponto relevante na atenção e práticas, também consideramos os aspectos objetivos como informação, dados estatísticos, dentre outros, e nesse contexto a intersubjetividade se fez presente na manifestação dialógica. Atentamos para um trabalho prioritariamente de comunicação, estando no centro da questão as linguagens.

\section{COMUNICAÇÃO E LINGUAGENS NA MEDITAÇÃO}

O diálogo foi ação essencial para uma relação autêntica, buscando promover a autonomia dos sujeitos em questão. Contudo, a princípios, identificamos que ainda estávamos presos ao paradigma assistencialista, onde a figura do profissional 
era central, com linguagem instrumental, e que gerou inseguranças e um consequente distanciamento do diálogo, com incoerências na expressão prática. Portanto, nos questionamos: $\mathrm{O}$ que precisamos saber sobre comunicação para podermos efetivar políticas de saúde eficazes? Seria importante compreender a perspectiva de linguagem para o desenvolvimento de novas práticas? O que significa linguagem instrumental e comunicativa, o que muda?

Apresentamos essa preocupação e tema como processo dinâmico que busca atualizações constantes, em uma atitude dialógica na organização dos saberes. Compreendemos que a educação em saúde sempre terá diferentes contextos e fomos modificando nossas visões de mundo, que implicou em uma mudança de atitude, abrindo espaços para novas descobertas, incluindo o que nos é mais essencial, a sensibilidade e inteligibilidade.

Identificamos nas práticas que valorizaram diversas linguagens os propósitos educativos em saúde, os quais acontecem a partir das relações de diálogo, e com elas vamos nos modificando, nos revelando e reinventando, tornando possíveis as transformações dos hábitos. A mudança de estilo de vida aconteceu quando os idosos ressignificaram entendimentos a partir das reflexões que permitem a franqueza e respeito às diversidades. As práticas do yoga, com seus princípios de equilíbrio, controle emocional e expressividade possibilitaram aos idosos entender seu corpo e experiências, com ampliação criativa e comunicativa. Foi interessante o quanto desejaram expressar suas conquistas e retomadas de condições vitais e sociais.

As intervenções com os idosos foram pautadas na didática comunicativa presentes nos movimentos do Yoga e na valorização dos seus elementos estéticos, com exercícios envolvendo Asanas (posturas) e cada um criou um movimento equilibrado. Em duplas, em frente a um papel pardo plotado na parede, enquanto um criava Asanas, o outro desenhava o contorno do corpo do seu colega. Todos experimentaram o processo de criar posturas e desenhar os corpos com atenção ao corpo em suas características e contornos.

Na prática percebemos o engajamento do grupo e características meditativas se fizeram presentes, contribuindo com os propósitos da atenção e concentração. Durante a intervenção, o grupo optou por utilizar adaptações como cadeiras ou cordas e colchões para auxiliar na permanência das posturas até que terminassem os desenhos. Após o primeiro momento, discutimos as relações com os desenhos, e perguntamos como eles se sentiram. A maioria achou os desenhos muito interessantes e bonitos, e expressaram: "Nossa! Como sou grande" (Idosa Lucia). Foram percepções manifestas a partir da oportunidade do olhar para si e sua imagem corporal. "Nunca me imaginei assim" (Idosa Antônia) foi uma fala que revelou o reconhecimento pessoal do corpo em diferentes dimensões, 
uma oportunidade de se ver de modo diferente, não apenas tradicionalmente no espelho ou auto-observação. Foi interessante o quanto ficaram atentamente observando, admirando os corpos. Perante as observações eles riram e brincaram com suas obras. Porém, poucos foram os relatos acerca de como se sentiram, pois tiveram muita dificuldade de expressar seus sentimentos. Talvez essa seja, de fato, a carência do século. Negligenciamos, muitas vezes, os nossos sentimentos e os atropelamos com argumentos racionais. A educação está carente do sensível-inteligível, portanto sentimos uma necessidade imperativa de um trabalho com os profissionais para alicerçar este aspecto tão importante para a educação e saúde.

Ao rever as atividades que movem a sensibilidade humana, conectada à inteligibilidade, foi possível refletir sobre os dualismos e a integração do ser humano que sente e pensa, e os idosos compreenderam o quanto nossos sentimentos foram excluídos da razão. Essa retomada foi fundamental para compreender nossos modelos e heranças. Descartes (1596-1650), com forte referência a ciência de Galileu Galilei (1564-1642), que se opunha radicalmente a filosofia Aristotélica concebia o corpo, não no estilo platônico, mas fazendo uma oposição do sensível e do inteligível. Descartes considerava o corpo humano uma grande máquina - o modelo mecanicista. Entretanto Descartes não apenas separou o corpo da alma, mas também não as juntou. (CARDIM, 2009).

Parece-nos claro que prevaleceu o pensamento dualista cartesiano influenciando fortemente todos os campos de pesquisa até hoje. No século XIX houve uma cisão entre a filosofia e a ciência, ambas buscavam explicar o fenômeno da totalidade humana. Desta forma duas correntes principais surgiram para tentar explicar o fenômeno: de um lado o empirismo que era constituído pelo conhecimento organicista e materialista do ser corporal e do outro o intelectualismo que se traduzia no conhecimento espiritualista da vida psíquica, intelectual e moral da alma humana. Em oposição ao paradigma dualista, Merleau-Ponty (2011) buscou conhecer profundamente ambas as correntes e desde seus primeiros trabalhos já fazia crítica severa tanto à filosofia, quanto à ciência. Acreditava que nenhuma das duas poderia abranger a totalidade humana. Merleau-Ponty (2014, p. 32) recupera alguns argumentos, abrindo caminhos para a construção de uma nova ontologia:

Nosso objetivo não é opor os fatos coordenados pela ciência objetiva outro grupo de fatos - sejam eles chamados "psiquismo" ou "fatos subjetivos", ou fatos interiores “- que "lhe escapam", mas mostrar que o ser-objeto e também o ser-sujeito, este concebido em oposição aquele e relativamente à ele, não constituem uma alternativa, que o mundo percebido está aquém ou além da antinomia, que o fracasso da psicologia "objetiva” deve ser compreendido juntamente com o fracasso da física "objetivista" - não como uma vitória 
do "interior" sobre o "exterior", do "mental" sobre o "material", mas como apelo à revisão de nossa ontologia, ao reexame das noções de "sujeito" e de "objeto".

A Ciência com seu esforço de objetivação acaba, muitas vezes, por encarar o ser humano como um organismo funcional e interpretá-lo a partir de propriedades físico-químicas para finalmente apresentar as leis de produção do comportamento humano. Contudo, o objeto da Educação Física é justamente compreender o comportamento, o sujeito em relação, e a base fundamental é a percepção humana, onde encontramos os alicerces para todas as formas de comportamento, como uma potência de sentidos, para assim compreender e nos aproximar deste fenômeno tão discutido por tantas áreas do conhecimento. A didática da Educação Física depende do olhar que lançamos para o comportamento humano que tem estreita ligação com o movimento e percepção, dois focos do trabalho da Educação Física.

Os processos metodológicos estão intimamente relacionados com a "didática comunicativa” (KUNZ, 2014). Envolvem subsídios teóricos e metodológicos capazes de contribuir para a efetivação de uma educação fundamentada nos princípios de emancipação, por meio de ações comunicativas embasadas em contextos culturais e sociais. A didática comunicativa tem a intenção de contribuir para a formação de sujeitos construtores de sua própria história e de uma sociedade mais justa e plural, levando-os a assumir uma "[...] posição de quem luta para não ser apenas objeto, mas sujeito também de sua História" (FREIRE, 1986, p. 60).

A fim de retomar a unidade e conexão corporal, buscamos com os idosos a sobreposição das imagens dos corpos desenhados, portanto mais de uma pessoa foi desenhada no mesmo papel pardo, deixando um efeito de duplicidade nas imagens. Com isso, tivemos a oportunidade de refletir sobre os diferentes corpos, e isto ficou bem evidente nos desenhos. Cada silhueta que ali estava era diferente da outra, e ainda que realizaram o mesmo movimento (símbolo representado pelo Asana específico), cada um realizou o movimento de acordo com as suas possibilidades e conforto, evidenciando a importância das diferenças e a riqueza de possibilidades de ser humano no mundo. O diálogo foi protagonizando o corpo relacional e reflexões acerca dos sujeitos sociais e culturais, além das diferenças conforme biotipo e o respeito à constituição pessoal. A amplitude dos pensamentos, expressões e sentimentos foi um momento fértil de abertura de consciência e promoveu motivações para prosseguir, envolvidas com muitas ações comunicativas em diferentes linguagens.

Os participantes reconheceram que uma racionalidade, com o sentido do esclarecimento, implica sempre numa racionalidade comunicativa. Devemos 
pressupor que a educação é sempre um processo onde se desenvolvem "ações comunicativas". Os idosos, enquanto sujeitos do processo de transformação, devem ser capacitados para sua participação dialógica na vida sociocultural.

A Didática comunicativa teve papel fundamental no processo de facilitação da comunicação, tanto dos profissionais da área de saúde quanto dos próprios idosos, na perspectiva da emancipação. Isso implicou em desenvolver determinadas competências humanas. Na proposta Crítico-Emancipatória (KUNZ, 2014), é valorizada a competência social como potencial para a aprendizagem coletiva e compreensão das relações socioculturais e contradições dessas relações; e a competência comunicativa, que envolve a expansão das diferentes linguagens na oralidade, escrita e a comunicação corporal. Saber se comunicar e entender a comunicação dos outros é um processo reflexivo e desencadeia iniciativas do pensamento crítico.

Para o desenvolvimento das competências, planejamos um processo educativo que foi baseado em Habermas (2003) e sua Teoria do Agir Comunicativo, que envolveu trabalho, interação e linguagem. Para a categoria trabalho, promovemos o desenvolvimento de capacidades e habilidades que possibilitaram aos idosos o agir com competência nas atividades de natureza prática, das habilidades envolvidas nas meditações e mais basicamente no Yoga. Para a categoria interação, promovemos possibilidades de um agir cooperativo, participativo e solidário com consciência das necessidades de superar situações conflituosas em relação aos papéis sociais e disponibilidade para a comunicação. Para a categoria linguagem, promovemos a possibilidade de ter acesso à espaços de diálogos que proporcionaram uma comunicação intersubjetiva por meio da linguagem comunicativa, bem como aos conteúdos simbólicos e linguísticos que transcendessem ao contexto. As expressividades nas meditações foram muito necessárias e evidentes, envolvendo um olhar ampliado para si e para o outro.

A razão da comunicação foi subsidiar e orientar a educação em saúde no sentido de propor reflexões e exercício da atenção. O encorajamento para as mudanças de comportamento ou do estilo de vida nem sempre são suficientes, mas sim, a sensibilização e o entendimento em prol da mudança que conduz a promoção de saúde. $\mathrm{O}$ favorecimento da meditação elevou desejos de ser e fazer nas práticas e propósitos. Buscamos a conquista de uma intervenção educacional que desconstruísse a busca do corpo ideal, perfeito, diante as exigências de beleza sociais atuais. Foi possível nas práticas de percepção corporal com os idosos questionar: Em que modelo está pautada a "promoção saúde e a educação em saúde" no pensamento coletivo? As relações com a valorização da vida e qualidade foram evidenciadas no desejo de viver dos idosos, demonstradas nos desejos de aceitação do corpo e sua constituição. 
A partir dos diferentes exercícios realizados e imagens corporais desenhadas pelos idosos surgiram questões envolvendo a obesidade e reconheceram o quanto o corpo obeso expressa uma constituição de "ser obeso". Na problemática envolvendo os estigmas, evidenciaram o quanto é necessário o amor próprio e o respeito pessoal e coletivo. Também refletiram sobre o controle do peso e cuidados à saúde, pois reconheceram o quanto a obesidade chegou a índices alarmantes e pode ser um desencadeador de uma série de complicações à saúde. O propósito da discussão e orientação, por parte do profissional de Educação Física, sobre a obesidade e como agente primário de prevenção e promoção da saúde, favoreceu esclarecimentos de que a obesidade e o sedentarismo são considerados problemas centrais em saúde pública.

Foi possível identificar a necessidade de criação de uma assistência educacional para as ações primárias à saúde, com estratégias e metodologias viáveis para atingir os idosos, com propostas que envolvem os profissionais de Educação Física inseridos nos Núcleos de Apoio à Saúde da Família (NASF). As orientações para as práticas corporais ampliadas, como a meditação, que consideram e promovem a expressividade e nelas reconhecem as problemáticas emergentes relacionadas à saúde são propostas necessárias.

Foi possível ampliar o olhar para o hoje, na experiência perceptiva que se traduz naquilo que não está determinado, mas que tem a potência geradora da expressão. O tempo não é algo material que se conserva dentro das coisas, ele está presente como um horizonte, um duplo horizonte; o passado e o futuro. No instante em que há uma relação entre eles, surge o fenômeno de fundação, onde encontramos a expressão de algo como totalidade, sem que ainda possam determinar. Esta transcendência escoa rumo ao não-ser. A expressão aparece por meio da intencionalidade operante que opera desde o início de forma escorregadia espontânea, inalcançável, mas que, entretanto, sentimos quando nos deparamos com os fenômenos. O ser-no-mundo é temporal, no movimento o corpo habita o mundo, o envolve e mistura-se a ele.

\section{CONSIDERAÇÕES FINAIS}

Nas práticas efetivadas no projeto de extensão "Envelhecimento saudável", os idosos participantes identificaram que precisamos estar em contato sensível, ter curiosidade e desejo de aprender. O corpo como nossa apresentação no mundo, que nos afeta e que é afetado por nós, necessita de constante atenção e envolvimento ampliando suas condições sensíveis e inteligíveis. Os idosos experimentaram 
amplamente o corpo e suas possibilidades, se reconectaram consigo mesmo, reconstruindo suas identidades sociais.

As práticas corporais que se apresentaram com brincadeiras adaptadas e yoga contribuíram para que ampliassem suas linguagens, permitindo, assim, maior expressividade e comunicação entre os pares. Reconhecer o próprio corpo foi condição para a retomada de consciência da inserção no/do mundo. O yoga e a meditação foram elementos que favoreceram essa conexão. A experiência vivida pelos idosos, de contato individual e com o outro, permitiu o reconhecimento e a valorização de um corpo que, muitas vezes, é estigmatizado por uma sociedade produtivista.

A experiência perceptiva foi aqui abordada à luz dos princípios de fundação (fimdierung), onde os dispositivos anatômicos do nosso corpo estabelecem uma relação de não-independência, fazendo que haja, desta forma, um apelo entre eles, uma espécie de documentação. Essa abertura possibilitou o surgimento de uma espontaneidade que se traduziu na expressão. Assim, no bojo da experiência, ocorreu a expressão de uma totalidade, que ainda não havia sido representada. Ela revelou-se a nós como um excesso, potência de significações, não somente como um em si, mas em comunidade e implicação mútua, de uma busca incessante pela vida e bem-estar.

A expressão não foi o surgimento de algo que se produz no interior, e que se mostra no exterior, mas sim a manifestação de algo que se fez nas relações, no movimento, no diálogo de abertura para o futuro. Esse processo possibilitou compreender o que estávamos fazendo, por meio de nossas experiências junto ao outro e ao mundo, pelos movimentos que realizamos e funções sensório-motoras, na imbricação ser humano e mundo.

O movimento humano espontâneo trouxe em seu bojo a dimensão temporal, que encontramos em uma totalidade que exprime, mesmo antes de representá-la. As totalidades expressas são os fenômenos, e tem o mesmo estofo da comunicação secreta, que faz uma "dança" sem que saibamos exatamente qual é a música. Tratamos de um ser de generalidades que por vezes é visível, por vezes é vidente, por vezes é sensível, por vezes é simbólico, por vezes é perceptivo, por vezes é cultura.

Nos movimentos que imprimiram diferentes linguagens e processos comunicativos a saúde foi contemplada em uma proposta ampliada que mobilizou os sujeitos, idosos, para ações conscientes e com retomada da totalidade corporal. A meditação foi essencial para favorecer diversas habilidades corporais e dimensões humanas. As PICS, envolvidas mais basicamente nas práticas de meditação, foram propósitos preventivos da saúde promoção e o cuidado integral, compartilhado e humanizado em saúde. 
Ocorreram conquistas de práticas que valorizaram as expressões em diferentes linguagens e promoveram as competências comunicativas dos idosos, ampliando relações sociais harmoniosas e valorização das capacidades individuais. As ações envolvendo meditações foram necessárias e fundamentais para os idosos, pois despertaram para o contato ampliado e relações sensibilizadoras do ser humano que deseja e promove a saúde. O movimento humano privilegiou a expressividade e atenção ao corpo, favorecendo relações de cuidado e consciência de si, do outro e do meio em que vivem.

\section{REFERÊNCIAS}

BRASIL. Ministério da Saúde. Secretaria de Atenção à Saúde. Departamento de Atenção Básica. Política nacional de práticas integrativas e complementares no SUS: atitude de ampliação de acesso. Ministério da Saúde. Secretaria de Atenção à Saúde. Departamento de Atenção Básica. - 2. ed., Brasília: Ministério da Saúde, 2018.

BRASIL. Lei no 8.080, de 19 de setembro de 1990 - e legislação Correlata. 2. ed., Porto Alegre: Corag; 2002.

BRASIL. Lei no 8.142 . Dispões sobre a participação da comunidade na gestão do sistema único de saúde (SUS) e sobre as transferências de recursos intergovernamentais de recursos financeiros na área de saúde e dá outras providencias. Diário Oficial 1990, $31 \mathrm{dez}$.

CARDIM, L. N. Corpo. São Paulo: Ed. Globo, 2009.

FREIRE, P.; SHOR, I. Medo e ousadia. 10. ed. Rio de Janeiro: Paz e Terra, 1986.

HABERMAS, J. Consciência moral e agir comunicativo. 2. ed. Rio de Janeiro: Tempo Brasileiro, 2003.

HUSSERL, E. Meditações cartesianas. São Paulo: Madras, 2001.

KUNZ, E. Transformação Didático-Pedagógica do Esporte. 8. ed. Injuí: Ed. Unijuí, 2014. 
MERLEAU-PONTY, M. Fenomenologia da percepção. Rio de Janeiro: Freitas Bastos, 2011.

MERLEAU-PONTY, M. O Visível e o Invisível. 4. ed. São Paulo: Editora Perspectiva, 2014.

SECRETARIA DE POLÍTICAS DE SAÚDE. Programa Nacional de Promoção da Atividade Física "Agita Brasil": Atividade física e sua contribuição para a qualidade de vida. Revista da Saúde Pública, v.36, n.2, p. 254-6, 2002. Disponível em: http://www.scielosp. org/pdf/rsp/v36n2/9222.pdf. Acesso em: jun. 2016.

WEOR, S. A. O Livro Amarelo: Manual Prático para Formar Arhats e Buddhas. São Paulo: IGB, 2009. 